\title{
THEORETICAL INVESTIGATION ON THE INFLUENCE OF PHYSICAL PARAMETERS ON SOOT AND NO $x$ ENGINE EMISSIONS
}

\author{
Arturo de Risi \\ Università di Lecce Dipartimento di \\ Ingegneria dell'Innovazione, \\ 73100 via Arnesano, Lecce - Italy
}

\author{
Teresa Donateo \\ ISUFI - Innovative Materials and \\ Technologies - Università di Lecce, \\ 73100 via Monteroni, Lecce - Italy
}

\author{
Domenico Laforgia \\ Università di Lecce -Dipartimento di \\ Ingegneria dell'Innovazione, \\ 73100 via Arnesano, Lecce - Italy
}

\begin{abstract}
CFD simulations need a certain number of parameters to calibrate both empirical and analytical models. The present investigation aims at identifying the effects of these parameters on the numerical prediction of a modified version of Kiva $3 \mathrm{~V}$ code, which includes the use of the RNG $k-\varepsilon$ model for turbulence, the gas/wall convective heat transfer model proposed by Han, Kelvin-Helmholtz Rayleigh-Taylor spray injection and breakup models. Ignition delay was modeled with the Shell model, whereas the laminar-turbulent characteristic time model was used for combustion. Soot formation and oxidation were calculated using Hiroyasu and Nagle and Strickland-Constable models, respectively. $\mathrm{NO}_{\mathrm{x}}$ was predicted by using the extended Zel'dovich mechanism.

This study was carried out for a common-rail direct injection, small-bore Diesel engine, including the investigation of both numerical and physical parameters. Numerical parameters are intended to be variables related to breakup, turbulence, and combustion models that are adjusted according to grid resolution, engine and injection system geometry, and operating conditions. In particular, the effect of laminar and turbulent time scales, characteristic breakup length and time scales, initial turbulence kinetic energy density, initial swirl velocity profile, on engine emissions was analyzed.

The investigated physical parameters were initial swirl ratio, air water content, Schmidt number for mass diffusion.

All simulations were performed by changing one of the above parameters at each run and keeping approximately the same pressure and heat release rate curves. Results show that similar pressure vs. crank angle curves can be obtained with different values of these parameters but they lead to very different values of predicted emissions levels. In particular, changes of laminar and turbulent characteristic time resulted in a strong influence on $\mathrm{NO}_{\mathrm{x}}$ emissions but their effects on soot levels were minor. Mass diffusion characteristics (e.g. Schmidt number) were found to strongly affect both soot and $\mathrm{NO}_{\mathrm{x}}$ emissions. Spray parameters were found mainly to affect soot formation. Furthermore, $\mathrm{NO}_{\mathrm{x}}$ and soot emissions showed a dependence on swirl ratio and velocity profile.
\end{abstract}

\section{INTRODUCTION}

The thermodynamics and fluid dynamics phenomena involved in a Diesel engine make this kind of internal combustion engines very challenging to model. The flow generated by the intake process is turbulent, compressible, unsteady and becomes two-phase and reacting after the injection event. The vaporized fuel reacts with air and burns producing pollutant emissions, which are controlled by details of air-fuel mixing and combustion processes.

The contemporary presence of these processes produces a wide range of length and time scales, which cannot be easily solved with the available computational resources. Thus, some small scale processes have to be represented by using submodels which introduce empiricism in computation. A consequence of this empiricism is the presence of "constants" in the submodels, which need to be changed according to engine specifications and operating conditions.

Some models' constants $\left(\mathrm{B}_{1}\right.$, swirl ratio, initial turbulent kinetic energy, etc.) should be derived by experimental investigations of injection systems and engine characteristics, because meaningless emissions levels could be predicted, if they are arbitrary chosen to match the engine pressure traces.

Both bulk gas motion (swirl, tumble, etc.) and turbulence characteristics are important in the fuel-air mixing and combustion processes. Thus, the intake flow process should be simulated by using a computation domain which includes the intake port geometry and moving valves in order to set up the initial conditions of spray and combustion event in the engine. Studies performed by Rutland et al. [1] showed that the influence of the intake flow on engine combustion modeling is very strong. The intake calculations were made by Rutland et al. on a full 3D mesh, whereas combustion calculations were performed on two different 60-degree mesh sectors taken from the same $3 \mathrm{D}$ intake flow data set. The flow field in the two sectors was characterized by an average swirl approximately $50 \%$ different in magnitude and opposite in direction. They found that pressure peaks occur at nearly the same crank angle 
in both cases, while the diffusion burn phase was quite different depending on the air-fuel mixing.

On the other hand, the initial flow turbulent conditions at intake valve closure could be determined using correlations derived from the full intake flow simulations. The initial turbulence kinetic energy, $k$, and its dissipation rate, $\varepsilon$, were defined as [2]:

$k=0.23 U^{2} ; \varepsilon=0.164 U^{3} \sqrt{A}$

where $\mathrm{U}$ is the average intake flow velocity through the valves and $\mathrm{A}$ is the average valve open area during intake. The proportionality constants were calculated by using the results of the whole $3 \mathrm{D}$ intake flow simulation.

The combustion model constants (laminar and turbulent time scales) are adjustable parameters since they take into account the necessity to use submodels, because of the discrete nature of control volume.

Adjusting the parameters of the combustion models that affect the laminar and turbulent characteristic times in order to match the experimental pressure trace of a baseline case is a procedure common to most KIVA researchers [3]. But predicted $\mathrm{NO}_{\mathrm{x}}$ and soot levels are strongly dependent on the values of these parameters. In particular, adjusting these parameters to match the peak of the experimental pressure trace, the predicted $\mathrm{NO}_{\mathrm{x}}$ values can be an order of magnitude lower than the experimental ones. Moreover, similar pressure curves can be obtained with different sets of these empirical constants, but the predicted emission levels can be quite different.

Kong et al. [18] obtained satisfactory results when the same model was applied to different injection systems changing only one model constant (the spray breakup time model constant).

Ogawa et al. [4] investigated the effects of swirl ratio on combustion characteristics, $\mathrm{NO}_{\mathrm{x}}$ and soot emissions by using a computational code named TurboKIVA. The experimental investigations showed that the heat release rate of the initial diffusion combustion increases and that the combustion period decreases as the swirl ratio increases. Therefore, soot emissions were reduced while $\mathrm{NO}_{\mathrm{x}}$ emissions increased.

However, the numerical simulation carried out by Ogawa et al. [4] proved that for a swirl ratio of 9.0, soot emissions

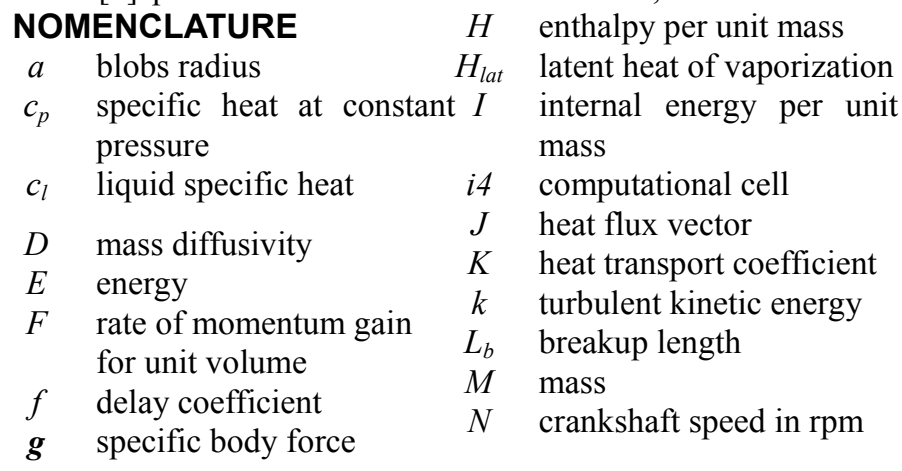

were higher than in the case of swirl ratio of 7.0, whereas $\mathrm{NO}_{\mathrm{x}}$ level remained almost constant suggesting that 7.0 is the optimum swirl ratio for minimizing soot emissions.

Uludogan et al. [22] studied the effect of engine speed on Soot and $\mathrm{NO}_{\mathrm{x}}$ production. The $\mathrm{NO}_{\mathrm{x}}$ production is well known to be dependent on the amount of mass which is at very high temperatures. At high speed, the swirl velocity is higher and the fuel vapor spreads out in the chamber enhancing the air-fuel mixing; thus, the amount of mass over $2600 \mathrm{~K}$ is low.

Finally, some input quantities (e.g. air composition and properties) are often considered negligible and standard values are used. It is well known that $\mathrm{NO}_{\mathrm{x}}$ concentration in the exhaust gas from diesel engines becomes higher in winter than in summer because of a change in the humidity of the atmosphere. Kondoh et al. [5] showed the empirical correction factor to predict the seasonal variation of $\mathrm{NO}_{\mathrm{x}}$ concentration from the point of view of the change in absolute humidity.

Ishida et al. [6] found that a change in absolute humidity of $+0.01 \mathrm{kgv} / \mathrm{kga}$ results in about $20 \%$ reduction of $\mathrm{NO}_{\mathrm{x}}$ due to a change of about $1 \%$ in specific heat of the burned zone gas. This is the basis of the use of water injection in diesel engines in order to reduce the $\mathrm{NO}_{\mathrm{x}}$ emissions. Ishida et al. showed that the earlier the injection, the larger the difference in $\mathrm{NO}_{\mathrm{x}}$ between the two cases.

Another effect of the use of submodels is the dependence of the air-fuel mixing prediction on the turbulent Schmidt number, which is defined as the ratio of turbulent viscosity and the turbulent diffusivity. Yi et al. [7] found that in 3D engine simulations, the turbulent Schmidt number should be varied according to grid resolution. In particular, the coarser the grid, the smaller the Schmidt number should be. If the grid is much coarser than the turbulent energy scale, the turbulent Schmidt number will be about 0.1 . However, as the grid size becomes smaller, the Schmidt number approaches the constant value of 0.6 .

For the present investigation, the KIVA code developed by Los Alamos laboratories has been chosen since it is one of the most comprehensive simulation codes, in particular a modified version of KIVA $3 \mathrm{~V}$ code which includes improved models has been used. A detailed description of these models is presented in the following section.

$n_{0}$ number of drops in the blobs pressure

$P_{\text {vap }} \quad$ vapor pressure

Pr Prandl number

$Q \quad$ heat transferred drop radius

$R^{*}$ universa gases

$R_{s} \quad$ swirl ratio

Re Reynolds number
Sc Schimdt number

Sh Sherwood number

$T$ temperature

$t$ time

u gas velocity vector

$\mathrm{U}$ average intake flow velocity

u' gas turbulence velocity vector

$V \quad$ cell volume

v drop velocity vector 


\begin{tabular}{|c|c|c|c|c|c|c|}
\hline $\begin{array}{l}\text { Y } \\
W\end{array}$ & $\begin{array}{l}\text { mass fraction } \\
\text { molecular weight }\end{array}$ & $\varepsilon$ & $\begin{array}{l}\text { turbulence dissipation } \\
\text { rate }\end{array}$ & $a$ & air & $\begin{array}{l}\text { phase } \\
\text { vapor phase }\end{array}$ \\
\hline $\boldsymbol{W} E$ & Weber number & $\lambda$ & wavelength & $c$ & combustion & \\
\hline$\Delta t$ & time step & $\mu$ & dynamic viscosity & $f$ & fuel mixture & $\underline{\text { Superscripts }}$ \\
\hline$\sigma$ & liquid surface tension & $v_{0}$ & diffusivity & $l$ & liquid phase / laminar & \\
\hline$\Lambda$ & $\begin{array}{l}\text { wavelength of the fastest } \\
\text { growing waves }\end{array}$ & $\rho$ & $\begin{array}{l}\text { density } \\
\text { characteristic time }\end{array}$ & $m$ & $\begin{array}{l}\text { combustion phase } \\
\text { chemical specie }\end{array}$ & $\begin{array}{l}\text { equilibrium value } \\
\text { combustion }\end{array}$ \\
\hline$\Omega$ & $\begin{array}{l}\text { maximum growth rate of } \\
\text { the growing waves }\end{array}$ & $\omega$ & angular velocity & $\begin{array}{l}p \\
s\end{array}$ & $\begin{array}{l}\text { parcel of drops } \\
\text { swirl }\end{array}$ & spray \\
\hline$\delta$ & Dirac delta function & Sub & cripts & $t$ & combustion & \\
\hline
\end{tabular}

\section{NUMERICAL MODELS}

\section{Governing equations}

Mass, momentum and energy equations used by KIVA for both laminar and turbulent flows can be written as [8]:

\section{Continuity equation for species $\mathrm{m}$}

$\frac{\partial \rho_{m}}{\partial t}+\nabla \bullet\left(\rho_{m} \mathbf{u}\right)=\nabla \bullet\left[\rho D \nabla\left(\frac{\rho_{m}}{\rho}\right)\right]+\frac{d \rho_{m}{ }^{c}}{d t}+\frac{d \rho^{s}}{d t} \delta_{m 1}$

Momentum equation for the fluid mixture:

$\frac{\partial(\rho \mathbf{u})}{\partial t}+\nabla \bullet(\rho \mathbf{u} \mathbf{u})=-\frac{1}{a^{2}} \nabla p-A_{0} \nabla\left(\frac{2}{3} \rho k\right)+\nabla \bullet \sigma+F^{S}+\rho \mathbf{g}$

where $A_{0}=0$ for laminar calculations, $A_{0}=1$ when the turbulence is activated. The symbol $a$ in eq. (3) is a dimensionless quantity related to the Pressure Gradient Scaling Method [8].

Internal energy equation

$\frac{\partial(\rho I)}{\partial t}+\nabla \bullet(\rho \mathbf{u} I)=-p \nabla \bullet \mathbf{u}+\left(1-A_{0}\right) \sigma: \nabla \mathbf{u}-\nabla \bullet \mathbf{J}+A_{0} \rho \varepsilon+\frac{d Q^{S}}{d t}+\frac{d Q^{c}}{d t}$

The heat flux vector $\mathrm{J}$ is the sum of heat conduction and enthalpy diffusion terms:

$\mathbf{J}=-K \nabla T-\rho D \sum_{m} H_{m} \nabla\left(\frac{\rho_{m}}{\rho}\right)$

where $d Q^{s} / d t$ and $d Q^{c} / d t$ are terms due to spray interactions and chemical heat, respectively.

The gases in the cylinder are assumed to be an ideal gas mixture: 
$p=R^{*} T \sum_{m} \frac{\rho_{m}}{W_{m}}$

$I(T)=\sum_{m} \frac{\rho_{m}}{\rho} I_{m}(T)$

$$
c_{p}(T)=\sum_{m} \frac{\rho_{m}}{\rho} c_{p m}(T)
$$

The transport coefficients are given by:

$$
\begin{aligned}
& \mu=\left(1.0-A_{0}\right) \rho v_{0}+\mu_{\text {air }}+A_{0} c_{\mu} \frac{k^{2}}{\varepsilon} ; \quad \mu_{\text {air }}=\frac{A_{1} T^{3 / 2}}{T+A_{2}} ; \\
& \lambda=A_{3} \mu ; K=\frac{\mu c_{p}}{\operatorname{Pr}} ; D=\frac{\mu}{\rho S c}
\end{aligned}
$$

The diffusivity $v_{0}$, Prandtl number and Schmidt number are input constants, $c_{\mu}=0.09$, and $A_{1}, A_{2}$ and $A_{3}$ are constants, which are set equal to $1.475 \times 10-5,110$ and $-2 / 3$, respectively.

\section{Turbulence model}

The modified RNG $\kappa-\varepsilon$ turbulence model proposed by Han and Reitz [9] has been adopted in the present investigation. This model differs from the standard RNG $\kappa-\varepsilon$ for the presence of an extra term in the dissipation equation that accounts for the compressibility of the flow. The modified RNG $\kappa-\varepsilon$ model [9] is able to predict the large scale structures that are produced by the squish flows and generated by the spray. These flow structures have an important impact on the prediction of $\mathrm{NO}_{\mathrm{x}}$ formation since it is very sensitive to the local temperatures in the combustion chamber.

The RNG $\kappa-\varepsilon$ model is formulated as:

$$
\begin{aligned}
& \frac{\partial \rho k}{\partial t}+\nabla \bullet(\rho \mathbf{u} k)=-\frac{2}{3} \rho k \nabla \bullet \mathbf{u}+\tau: \nabla u \\
&+\nabla \bullet\left(\alpha_{k} \mu \nabla k\right)-\rho \varepsilon+\frac{d W^{s}}{d t} \\
& \frac{\partial \rho \varepsilon}{\partial t}+\nabla \bullet(\rho \mathbf{u} \varepsilon)=-\left[\frac{2}{3} C_{1}-C_{3}+\frac{2}{3} C_{\mu} C_{\eta} \frac{k}{\varepsilon} \nabla \bullet \mathbf{u}\right] \rho \varepsilon \nabla \bullet \mathbf{u} \\
&+\nabla \bullet\left(\alpha_{\varepsilon} \mu \nabla \varepsilon\right)+\frac{\varepsilon}{k}\left[\left(C_{1}-C_{\eta}\right) \tau: \nabla \bullet \mathbf{u}-C_{2} \rho \varepsilon+C_{s} \frac{d W^{s}}{d t}\right.
\end{aligned}
$$

where

$$
\begin{aligned}
& C_{3}=\frac{-1+2 C_{1}-3 m(n-1)+(-1)^{\delta} \sqrt{6} C_{\mu} C_{\eta} \eta}{3} \\
& \delta=1 ; \quad \text { if } \nabla \bullet \mathbf{u}<0 \\
& \delta=0 \quad \text { if } \nabla \bullet \mathbf{u}>0 \\
& C_{\eta}=\frac{\eta\left(1-\eta / \eta_{0}\right)}{1+\beta \eta^{3}}
\end{aligned}
$$

$\eta$ is the ratio of turbulent to mean strain time scale and the other constants are reported in table 1 .

\begin{tabular}{|cc|cc|}
\hline$C_{\mu}$ & 0.0845 & $\eta_{0}$ & 4.38 \\
\hline$C_{1}$ & 1.42 & $\beta$ & 0.012 \\
\hline$C_{2}$ & 1.68 & $\mathrm{~m}$ & 0.5 \\
\hline$\alpha_{k}=\alpha_{\varepsilon}$ & 1.39 & $\mathrm{n}$ & 1.4 \\
\hline
\end{tabular}

\section{Table 1 - Constants values for RNG k- $\varepsilon$ turbulence} model.

The initial value of the turbulent kinetic energy density $\mathrm{k} 0$ is given in input as a percentage of the kinetic energy based on the mean piston speed ( $k=2 k_{0} U^{2}$ ).

For non engine application $\mathrm{k}_{0}$ is usually set equal to $10 \%$, while in the case of engine applications, $\mathrm{k}_{0}$ should be measured experimentally or calculated by simulating the intake flow process .

From 3-D intake flow simulations, Rutland and al. [2] found the value of the constant in the correlation between the initial turbulent level and the average intake flow velocity through the valves to be equal to $\mathrm{k}_{0}=0.115$. By using this value of $\mathrm{k}_{0}$, the turbulent kinetic energy $\mathrm{k}$ and its dissipation rate are given by equation (1).

\section{Swirl model}

The swirl is an organized rotation of the load around the cylinder axis, which is created by the intake process and persists during the compression, combustion, and expansion processes. The KIVA $3 \mathrm{~V}$ code allows the initial value of the swirl ratio to be set. The swirl ratio is defined as the ratio between the angular velocity of a solid-body rotating flow $\omega_{s}$, with the same angular momentum of the actual flow, and the crankshaft angular rotational speed $\left(R_{s}=\omega_{s} / 2 \pi N\right)$.

The level of swirl motion is not uniform throughout the chamber. The turbulent wall boundary layer produces a reduction of the swirl velocity near the walls. Thus, the swirl velocity cannot be assumed to have a wheel-flow profile.

Experimental investigations showed that the swirl profile can be modeled by using a parametric Bessel function. The parameter $\alpha$ is a dimensionless constant which defines the initial azimuthal velocity profile. It lies between 0.0 (the wheel flow limit) and 3.83 (zero velocity at the wall) [8]. 


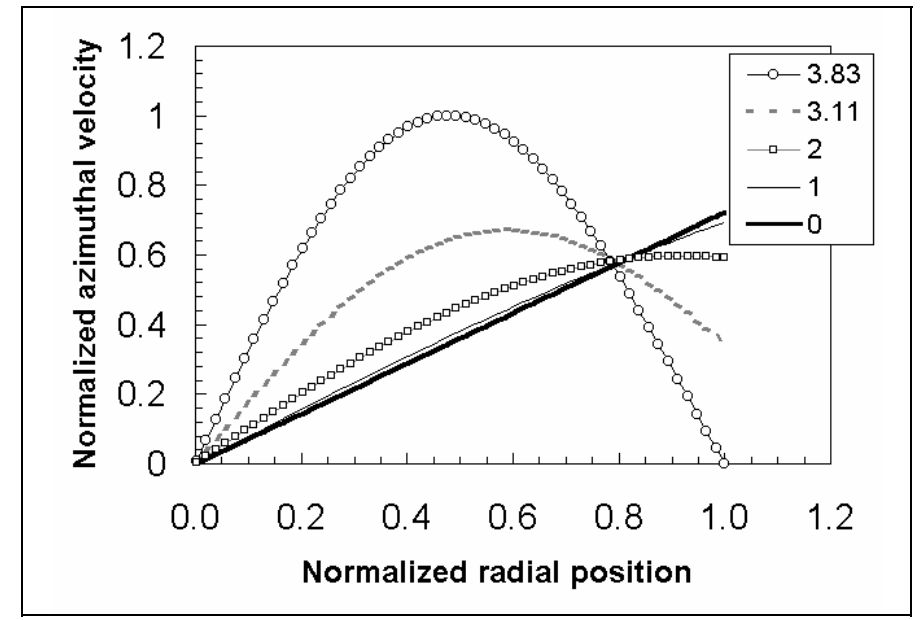

Figure 1 - Swirl velocity profile.

Figure 1 illustrates the Bessel profile for different values of $\alpha$. The Bessel function profile is defined in order to give the same angular momentum as wheel flow with the same swirl number. Thus, higher values of $a$ correspond to higher the initial slope of the Bessel curve.

Wahiduzzaman and Ferguson [10] suggested the value of 3.11 for typical engine applications.

\section{Spray models}

A stochastic approach similar to that of Dukowicz [11] was used to perform liquid injection. Fuel is simulated to be injected as parcels of big drops, or "blobs", having a radius equal to the effective nozzle radius [22]. All injected parcels have the same velocity, the same thermodynamic properties, the same initial mass and, therefore, the same number of blobs. The initial mass is calculated by using equation (12) and the number of drops or "blobs" in each parcel is given by

$n_{0}=\frac{p m_{i n j}}{\frac{4}{3} \pi \rho_{l}\left(r_{\text {noz }}\right)^{3}}$

$p m_{i n j}=\frac{m f_{i n j}}{t n_{\text {parc }}}$

Where $m f_{i n j}$ and $t n_{\text {parc }}$ are the total injected fuel mass and the total number of parcels injected during the whole injection respectively. $r_{n o z}$ is the nozzle radius. The number of parcels injected in the unit time is determined from the measured mass flow rate.

\section{Breakup model}

After injection, blobs undergo a breakup process that removes mass from the blobs and forms new child drops, whose radius $r$ can be predicted by using the stability analysis of cylindrical liquid surfaces perturbed by an axisymmetric displacement [12]

$$
\begin{array}{ll}
r=B_{0} \Lambda & \text { if } B_{0} \Lambda \leq a \\
r=\min \left[\left(\frac{3 \pi a^{2} u}{(2 \Omega)}\right)^{0.33},\left(\frac{3 a^{2} \Lambda}{4}\right)^{0.33}\right] & \text { if } B_{0} \Lambda>a
\end{array}
$$

where $\mathrm{B}_{0}$ is a constant equal to 0.61 and $a$ indicates the "blob" radius whose rate-of-change due to breakup is assumed to be equal to:

$\frac{d a}{d t}=-\frac{(a-r)}{\tau}$

where $\tau=3.726^{B_{1} a} / \Lambda \Omega$ and $B_{1}$ is an adjustable constant that depends on the nozzle geometry.

The wavelength and the maximum growth rate of the fastest growing waves, can be calculated with analytical correlations as a function of the spray parameters [12]:

$$
\begin{aligned}
& \frac{\Lambda}{a}=9.02 \frac{\left(1+0.45 Z^{0.5}\right)\left(1+0.4 T^{0.7}\right)}{\left(1+0.87 W e_{g}^{1.67}\right)^{0.6}} \\
& \Omega\left(\frac{\rho_{1} a^{3}}{\sigma}\right)^{0.5}=\frac{\left(0.34+0.38 W e_{g}^{1.5}\right)}{(1+Z)\left(1+1.4 T^{0.6}\right)}
\end{aligned}
$$

where $Z=\left(W e_{1}\right)^{0.5} / R e_{1}$ is the Ohnesorge number, $T=Z\left(W e_{g}\right)^{0.5}$, $W e_{i}=\rho_{i} \mathbf{u}^{2} a / \sigma$ with $\mathrm{i}=1, \mathrm{~g}$ is the Weber number and $R e_{1}=u_{a} / \mu_{1}$. In the above definitions, $a$ is the liquid jet radius, $\boldsymbol{u}$ is the relative velocity vector between liquid and gas, $\mu_{1}$ is the liquid cinematic viscosity and the subscripts 1 and $g$ refer to liquid and gas phase, respectively. However, diesel spray penetration has different rates within and beyond the breakup length for the existence of an intact core close to the nozzle [13]. To account for this behavior, a model including both Kelvin-Helmotz and Reyleigh-Taylor instability criteria has been proposed by Reitz [14]. According to this model, breakup is due to K-H instability until the spray reaches the breakup length, then breakup occurs due to both $\mathrm{K}-\mathrm{H}$ and $\mathrm{R}-\mathrm{T}$ mechanisms. The value of the breakup length, $L_{b}$, is given by:

$L_{b}=C d \sqrt{\frac{\rho_{l}}{\rho_{g}}}$

where $\mathrm{C}$ is an adjustable parameter that depends on the nozzle and $d$ is the droplet diameter. Senecal [15] and Beale et al. [14] suggested that the value of the constant $\mathrm{C}$, in the limit of high Weber numbers, is equal to $\mathrm{B}_{1} / 2$, according to the following reasoning. 
In the hypothesis of negligible liquid viscosity and gas-phase Weber number approaching infinity, the break-up time ( $\left.\tau=3.726 B_{1} a / \Lambda \Omega\right)$ in the KH model can be reduced to:

$$
\tau=\frac{B_{1} r}{u} \sqrt{\frac{\rho_{l}}{\rho_{g}}}
$$

where $u$ is the relative velocity.

Thus, the breakup length, which is assumed to be $L_{b}=\tau u$, can be calculated by:

$L_{b}=B_{1} r \sqrt{\frac{\rho_{l}}{\rho_{g}}}$

By comparing eq. 19 and eq. 17, it is possible to obtain:

$C=B_{1} / 2$

Yet, neglecting liquid viscosity but considering surface tension, the analytical fastest growing frequency, $\Omega_{t}$ and the corresponding wave number $\mathrm{K}$ predicted by $\mathrm{RT}$ instability criteria are given by [14]:

$\Omega_{t}=\sqrt{\frac{2}{3 \sqrt{3 \sigma}} \frac{\left[g_{t}\left(\rho_{l}-\rho_{g}\right)\right]^{3 / 2}}{\rho_{l}+\rho_{g}}}$

$\mathrm{K}=\sqrt{\frac{-g_{t}\left(\rho_{l}-\rho_{g}\right)}{3 \sigma}}$

where $g_{t}$ is the acceleration in the direction of travel.

\section{Combustion models}

The multistep Shell ignition model [16] was used in conjunction with the laminar and turbulent characteristic time combustion model [17] to describe the entire combustion process. A temperature threshold of $1100 \mathrm{~K}$ was chosen to switch from ignition chemistry $(\mathrm{T}<1100 \mathrm{~K})$ to combustion chemistry $(\mathrm{T}>1100 \mathrm{~K})$.

The Shell model introduces a simplified set of generic reactions and species to account for the multistage ignition and cool flame phenomena that have been observed with hydrocarbon fuels. The kinetic parameters of the model were described by Kong et al. [18]

An important aspect of the combustion model is the appropriate formulation of the characteristic time which is the sum of a laminar timescale and a turbulent timescale.

The time rate of change of the partial density of species to another, is given by $\frac{d Y_{m}}{d t}=-\frac{Y_{m}-Y_{m}^{*}}{\tau_{c}}$

where $Y_{m}$ is the mass fraction of species $m, Y^{*}{ }_{m}$ is the local and instantaneous thermodynamic equilibrium value of the mass fraction and $\tau_{c}$ is the characteristic time to achieve this equilibrium. The characteristic time $\tau_{c}$ is assumed to be the same for the seven species considered in the combustion model and consists of a laminar timescale and a turbulent timescale:

$\tau_{c}=\tau_{l}+f \tau_{t}$

The delay coefficient $f$ represents the influence of turbulence on combustion after ignition has occurred, and was assumed to be given by:

$f=\frac{1-e^{-r}}{0.632}$

The parameter $r$ indicates the completeness of combustion in a specific region. Its value varies from 0 (no combustion yet) to 1 (complete consumption of fuel and oxygen).

The laminar timescale depends on the local concentrations of fuel and oxygen and is influenced by temperature, while the turbulent time scale is proportional to the eddy turnover time [18].

$$
\begin{aligned}
\tau_{l} & =A^{-1}\left[C_{14} H_{30}\right]^{0.75}\left[O_{2}\right]^{-1.5} \exp (-E / R T) \\
\tau_{t} & =C_{2} \frac{k}{\varepsilon}
\end{aligned}
$$

Usual values of $\mathrm{C}_{2}$ are: $\mathrm{C}_{2}=0.142$ if the standard $\mathrm{k}-\varepsilon$ model is used, or $\mathrm{C}_{2}=0.1$ if the RNG $\mathrm{k}-\varepsilon$ model is used. $\mathrm{E}=77.3 \mathrm{~kJ} / \mathrm{mol}$ for tetradecane.

Combustion is strongly influenced by turbulence which affects the mixture transport properties and the mixing of the reactants. However, the initiation of combustion, which corresponds to the pre-mixed combustion phase, is governed by the laminar timescale, while turbulence starts be more influent only after the autoignition event. Eventually, the combustion will be dominated by turbulent mixing effects in the regions of $\tau_{l}<\tau_{t}$ (mixing control burning phase). Because of this, the laminar timescale is more influent in the region near the injector where the turbulent timescale is very small due to the high injection velocity.

\section{Emissions models}

The soot emission models adopted in this study are the Hiroyasu formation model [19] and the Nagle and StricklandConstable oxidation model [20]. 
Soot concentration is predicted by a single step equation which considers the temporal rate of change of the soot mass due to the rates of formation and of oxidation:

$\frac{d M_{\text {soot }}}{d t}=\frac{d M_{\text {soot }}^{\text {form }}}{d t}-\frac{d M_{\text {soot }}^{\text {oxid }}}{d t}$

Where the rate of formation has the following expression:

$\frac{d M_{\text {soot }}^{\text {form }}}{d t}=A_{\text {soot }}^{\text {form }} M_{\text {fuel }}^{\text {vap }} \sqrt{P} \exp \left(-\frac{E_{\text {soot }}^{\text {form }}}{R T}\right)$

with $E_{\text {soot }}^{\text {form }}=12,500 \mathrm{cal} / \mathrm{mole}$.

While the oxidation rate, assumed to be proportional to the mass of soot, $\mathrm{M}_{\mathrm{soo}} \mathrm{t}$, is given by:

$\frac{d M_{\text {soot }}^{\text {oxid }}}{d t}=\frac{6}{\rho_{\text {soot }} D_{\text {soot }}} \dot{W}^{\prime \prime}{ }_{N S C} M_{\text {soot }}$

where $\dot{W}^{\prime \prime}{ }_{N S C}$ is the oxidation rate per unit surface area $\left(\mathrm{g} / \mathrm{s} * \mathrm{~cm}^{2}\right)$ of the mass of soot.

NO emissions are modeled with the Zel'dovich mechanism, according to the following equations:

$\mathrm{O}+\mathrm{N}_{2} \leftrightarrow \mathrm{NO}+\mathrm{N}$

$\mathrm{N}+\mathrm{O}_{2} \leftrightarrow \mathrm{NO}+\mathrm{O}$

$\mathrm{N}+\mathrm{OH} \leftrightarrow \mathrm{NO}+\mathrm{H}$

where the forward and backward equilibrium constants for the three reactions reported above are:

Reaction 1

$\mathrm{k}_{1 \mathrm{f}}=7.6 \cdot 10^{13} \cdot \exp (-38,000 / \mathrm{T})$;

$\mathrm{k}_{1 \mathrm{~b}}=1.6 \cdot 10^{13}$;

Reaction 2

$\mathrm{k}_{2 \mathrm{f}}=6.4 \cdot 10^{9} \cdot \mathrm{T} \cdot \exp (-3,150 / \mathrm{T})$;

$\mathrm{k}_{2 \mathrm{~b}}=1.5 \cdot 10^{9} \cdot \mathrm{T} \cdot \exp (-19,500 / \mathrm{T})$;

Reaction 3

$\mathrm{k}_{3 \mathrm{f}}=4.1 \cdot 10^{13}$;

$\mathrm{k}_{3 \mathrm{~b}}=2.0 \cdot 10^{14} \cdot \exp (-23,650 / \mathrm{T})$;

\section{NUMERICAL SIMULATIONS}

The effect of the investigated input parameters on the predicted emission levels has been analyzed by comparing the computational results with experimental data of a direct injection diesel engine equipped with a common rail injection system.

The experimental data were acquired by using a commercial small bore high speed engine, provided with adequate instrumentation for its control and for the measurement of emissions and performance parameters.

The engine specifications are summarized in table 2 .

\begin{tabular}{|l|l|}
\hline Number of cylinders & 4 \\
\hline Bore & $88.0[\mathrm{~mm}]$ \\
\hline Stroke & $88.4[\mathrm{~mm}]$ \\
\hline Connecting rod length & $149[\mathrm{~mm}]$ \\
\hline Compression ratio & 19 \\
\hline Intake valves closing (IVC) & $173^{\circ}$ BTDC \\
\hline No nozzles & 6 \\
\hline Nozzle diameter & $169[\mu \mathrm{m}]$ \\
\hline Injection system & Common Rail \\
\hline
\end{tabular}

Table 2 - Engine specifications.

The injection was performed by using a 6 hole VCO nozzle centrally located in an axisymmetrical geometry. Thus, to reduce the computational time, a 60 degrees sector mesh was used, characterized by 20 cells in the radial direction, 20 cells in the longitudinal direction and 27 cells in the axial direction, with a minimum of 17 cells at TDC. The cylinder dome has a conic shape while combustion chamber geometry was a reentrant bowl.

The engine was run at $2800 \mathrm{rev} / \mathrm{min}$ and at $50 \%$ load. The operating conditions for simulations are summarized in table 3 .

\begin{tabular}{|l|l|}
\hline Total injected mass & $27.8[\mathrm{mg}]$ \\
\hline Injection duration & $17.4^{\circ}$ \\
\hline Pressure at IVC & $0.17[\mathrm{MPa}]$ \\
\hline Temperature at IVC & $325[\mathrm{~K}]$ \\
\hline Engine speed & $2800[\mathrm{rpm}]$ \\
\hline Start of injection & $15 \mathrm{BTDC}$ \\
\hline
\end{tabular}

Table 3 - Operating condition for engine simulations.

The simulations were performed by choosing a combination of standard values of the input quantities and varying each input quantity one at a time. The baseline set of input constant is reported in table 4 . The composition of intake air corresponds to a relative humidity equal to $50 \%$.

With this set of input data the simulation code predicts a level of $\mathrm{NO}_{\mathrm{x}}$ emissions of $46 \mathrm{~g} / \mathrm{kg}_{\text {fuel }}$ which is about $30 \%$ lower than the experimental one $\left(65 \mathrm{~g} / \mathrm{kg}_{\text {fuel }}\right)$. A comparison between experimental and numerical pressure vs. crank angle curves revealed that the compression and expansion pressure traces match the experimental ones very well, but the numerical pressure peak exceeds the numerical one of $11 \%$.

These numerical results could be "improved" by changing some input quantities in order to match the pressure trace or the $\mathrm{NO}_{\mathrm{x}}$ emission level. In order to achieve realistic results, it is important to be aware of the meaning of these input data and analyze the effect of their variation.

\begin{tabular}{|l|l|l|l|}
\hline Input quantity & Description & Ref. & Value \\
\hline
\end{tabular}




\begin{tabular}{|l|l|c|l|}
\hline Rs & initial swirl ratio & Page 4 & 0.65 \\
\hline$\alpha$ & $\begin{array}{l}\text { constant defining the initial swirl } \\
\text { velocity profile }\end{array}$ & - & 3.11 \\
\hline $\mathrm{k}_{0}$ & initial turbulence kinetic energy & eq. 1 & 1.6 \\
\hline MFRAC(isp) & composition of intake air & eq. 6-8 & - \\
\hline RSC & $\begin{array}{l}\text { reciprocal of the Schmidt } \\
\text { number for mass diffusion }\end{array}$ & eq. 9 & 1.78 \\
\hline $\mathrm{C}_{2}$ & $\begin{array}{l}\text { constant used in calculating the } \\
\text { turbulent combustion time }\end{array}$ & eq. 27 & 0.1 \\
\hline $\mathrm{A}$ & $\begin{array}{l}\text { constant used in calculating the } \\
\text { laminar combustion time }\end{array}$ & eq. 26 & 20 \\
\hline $\mathrm{B}_{1}$ & $\begin{array}{l}\text { time constant for the Kelvin } \\
\text { Helmholtz breakup model }\end{array}$ & eq. 18 & 25 \\
\hline
\end{tabular}

Table 4 - Input constants for the baseline case.

Some input quantities (Rs, $\mathrm{K}_{0}, \mathrm{~A}, \mathrm{HUMIDITY}, \mathrm{RSC}$ ) give roughly the same pressure trace but modify the predicted emissions levels. Others influence both the average cylinder pressure and the $\mathrm{NO}_{\mathrm{x}}$ and/or soot levels. In particular, by increasing $\mathrm{B}_{1}$ up to 40 (and changing the breakup length to satisfy eq. 20) it is possible to match the peak of the pressure curve without changing the predicted $\mathrm{NO}_{\mathrm{x}}$ level significantly ($2 \%$ ), but this value corresponds to a breakup length of $20 \mathrm{~mm}$, that is the radius of the bowl. Moreover, the expansion curve is not yet matched with $B_{1}$ equal to 40 . On the other hand, choosing $\mathrm{C}_{2}$ equal to 2 the predicted pressure peak becomes closer to the experimental one, but the ignition delay and the NO value are strongly modified, being affected by the turbulent characteristic time.

\section{Effect of air flow characterization}

\section{Water content (HUMIDITY).}

The effect of the intake water content on the predicted emissions levels has been tested by changing the relative humidity from $30 \%$ to $90 \%$.

The results obtained by these simulations show that the higher the humidity level, the lower the heat released during the premixed combustion phase. Thus, the soot formation increases as humidity increases, while the extension of very high temperature regions decreases leading to lower NO levels.

The effect of humidity on emissions level is shown in figure 2. By increasing humidity from $30 \%$ to $90 \%$ the predicted $\mathrm{NO}_{\mathrm{x}}$ level reduction is about $14 \%$. As far as the soot production is concerned, soot increases by $5 \%$ as the humidity is changed from $30 \%$ to $90 \%$.

Humidity affects three important factors which influence NO emissions: the molecular weight of air, the specific heat of the mixture (eq. 8) and the average gas temperature during combustion. In particular, increasing humidity the gas weight increases, the specific heat increases and the average temperature is lower.

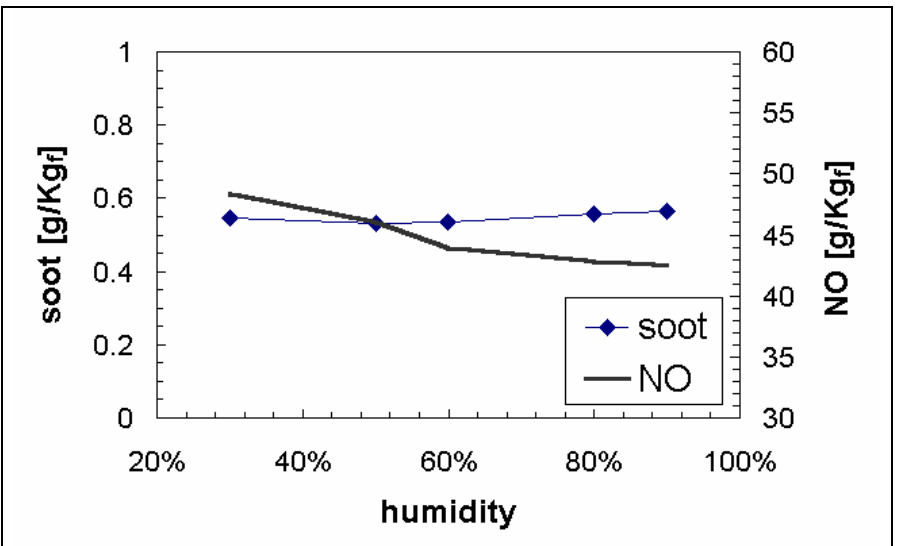

Figure 2 - Emission levels versus relative humidity.

It has been shown, both numerical and experimentally [6] that main effect of increasing humidity is the increase in the mixture specific heat.

If the specific heat increases, the heating up of the mixture gets slower, thus the air temperature is lower and the air-spray heat exchange diminishes. As a consequence of this effect, the vaporization rate decreases and the heat release rate during the premixed combustion phase decreases.

\section{Charge motion within the cylinder (Rs, $\alpha, \mathrm{K}_{0}, \mathrm{RSC}$ ).}

The charge motion within the cylinder includes both bulk (swirl, tumble, squish) and turbulent motion.

The turbulent flow field is defined by choosing the initial turbulence kinetic energy, the turbulent Schmidt number and the initial swirl which increases the turbulent kinetic energy during the compression stroke. These input parameters are very important since the turbulent characteristic time (eq. 23-24) is governed only by the turbulence flow field when the parameter $\mathrm{C}_{2}$ is kept constant.

The laminar Schmidt number is function of fluid properties such as viscosity and molecular diffusivity. The turbulent Schmidt number, instead, is function of the state of turbulence, since it measures the relative diffusion of momentum and mass due to turbulence. The turbulent Schmidt number is defined as the ratio between the turbulent viscosity and the turbulent diffusivity.

The turbulent flow within the cylinder involves the formation of eddies which cover many length scales. To completely resolve the turbulent flow, the computational grid size should be smaller than the smallest eddies, but the available computational resources limit such refinement of grid. 


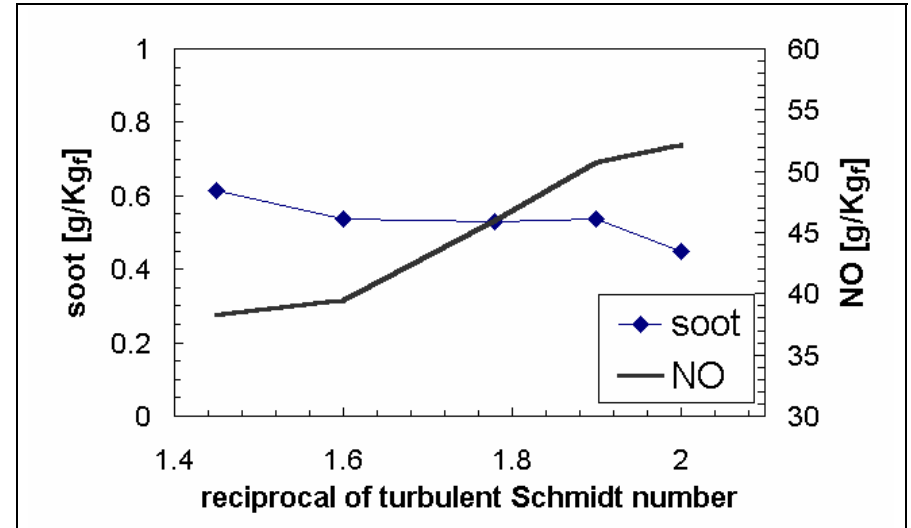

Figure 3 - Emission levels versus RSC

If the grid is coarse compared to the turbulent length scales, the smallest length scales are unresolved, and the mixture diffusivity is underestimated. To correct this bias, the turbulent Schmidt number should be decreased according to grid size .

Yi et al. [7] found that if the grid is much coarser than the turbulent energy scale, the turbulent Schmidt number is about 0.1 . However, as the grid size becomes smaller, the Schmidt number approaches the constant value of 0.6.

They also showed that, for a fixed mesh size, the predicted fuel air mixing decreases as the Schmidt number increases. Therefore, the ignition delay is expected to decrease with the increasing of RSC (the reciprocal of the turbulent Schmidt number).

The results of numerical simulations carried out in the present investigation by increasing RSC from 1.45 to 2.0 are consistent with this prediction. Due to the enhanced mixing, the soot emissions decrease, while the NO levels increase. The variation of both emissions are of about $30 \%$.

The increasing of $\mathrm{NO}_{\mathrm{x}}$ levels with RSC increasing can also be explained by considering the effect of the turbulence viscosity which is related to the turbulence level $\left(v_{t}=C_{\mu} k^{2} / \varepsilon\right)$.

As the turbulent viscosity diminishes, the smoothing of the local temperature differences is limited and the $\mathrm{NO}_{\mathrm{x}}$ concentration increases.

Stephenson et al. [21] performed a parametric study of the effect of swirl flow and pre-injection turbulence level on fuel vaporization, mixing and combustion processes by using KIVA code.

They found that, in the case of constant chamber volume, the initial turbulence has a significant effect on the time to reach the $1500 \mathrm{~K}$ and $2000 \mathrm{~K}$ thresholds. By increasing the turbulent kinetic energy, the air fuel mixing is enhanced, and the amount of high temperature mass increases. Therefore, a higher level of initial turbulent kinetic should lead to higher $\mathrm{NO}_{\mathrm{x}}$ levels and faster soot oxidation.

Figure 4 shows the soot and NO levels versus initial turbulent kinetic energy as $\mathrm{k}_{0}$ is increased from 0.4 to 1.6 . It is possible to notice that the NO levels are roughly constant with $\mathrm{k}_{0}$ The soot oxidation decreases by about $8 \%$ for $\mathrm{k}_{0}$ increasing from 0.4 to 1.2 .

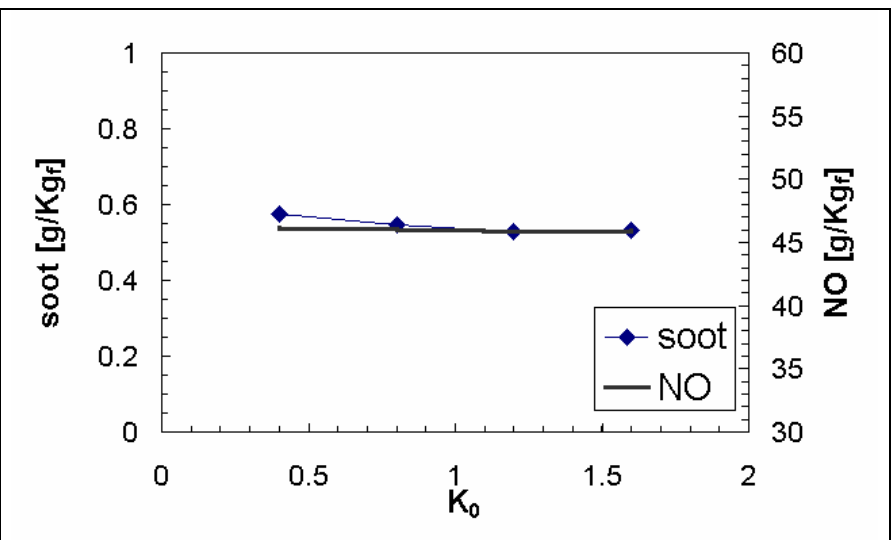

Figure 4 - Emission levels versus initial turbulent kinetic energy.

The small influence of this input parameter comes as no surprise because the turbulence level at the injection event is governed more by the swirl motion during the compression stroke than by the initial conditions of the flow in the case of engine simulations.

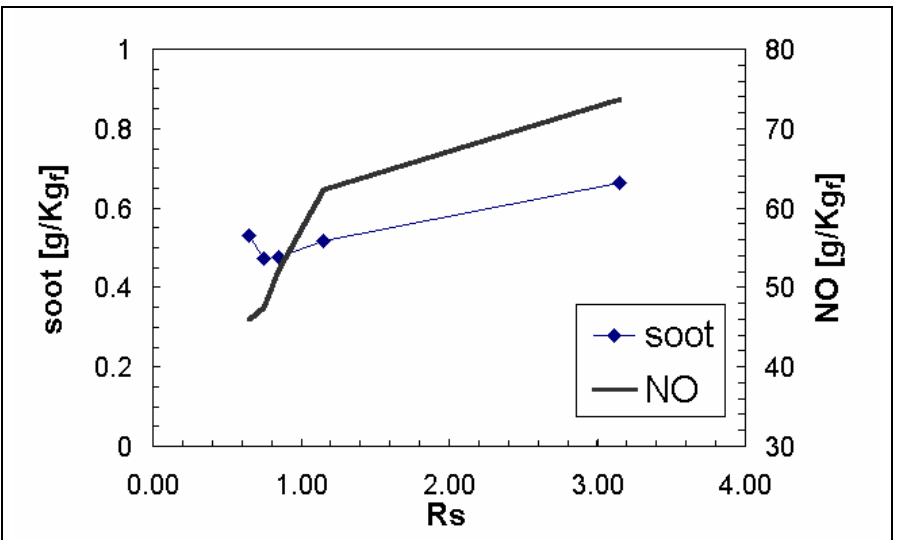

Figure 5 - Emission levels versus initial swirl ratio.

The role of swirl in diesel engines is very important since it affects not only the vaporization and fuel-air mixing processes but also wall heat transfer during compression and, therefore, the charge temperature at injection event.

The fuel-air mixing rate and the heat released during the premixed and mixing-controlled combustion phases are increased by higher swirl ratios.

The charge motion due to swirl improves the mixing and accelerates the combustion process. Thus, the pressure peak increases by about $5 \%$ as the swirl ratio is increased from 0.65 to 3.15 and the NO levels increase by $60 \%$ (figure 5 ).

The soot produced by the combustion process diminishes for small increases in swirl ratio $(0.65-0.85)$. This is probably due to the enhanced spreading out of the soot during the expansion 
stroke caused by the centrifugal forces. However, for higher swirl levels, there is another effect to consider. Due to the high swirling flow each spray is deviated towards the center of the chamber, increasing the amount of vaporized fuel in this region where the soot oxidation is prevented, due to the reduced presence of air. Moreover, the reentrant bowl shape produces an additional reduction of volume available for air-fuel mixing near the cylinder axis. Finally, when the swirl ratio is very high (3.15) the sprays produced by the six holes of the nozzle interfere producing an additional increasing of soot.

These results are consistent with numerical results found by Ogawa et al. [4].

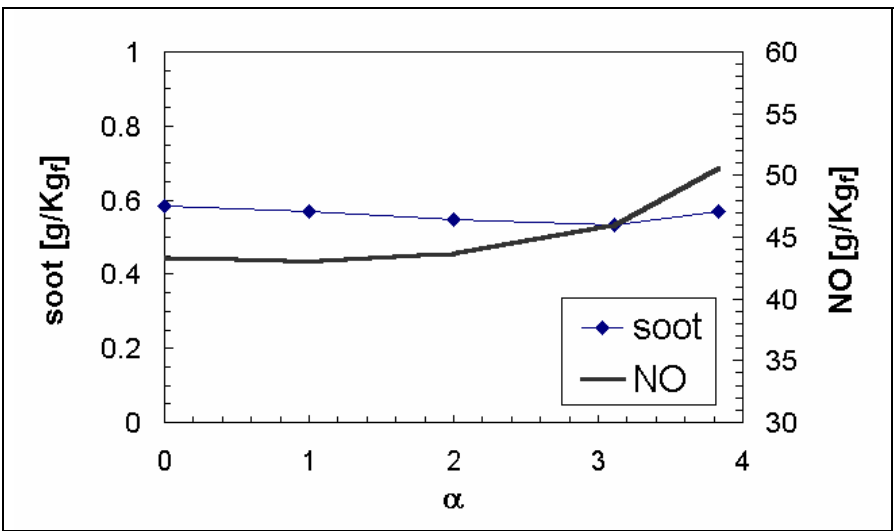

Figure 6 - Emission levels versus Bessel profile parameter.

The swirl profile within the chamber is calculated with a Bessel function which depends on the dimensionless factor $\alpha$. Figure 1 shows the swirl velocity profile as $\alpha$ is changed from 0.0 (wheel flow profile) to 3.83 (zero velocity at walls), calculated for the constant Rs value of 0.65 . It is possible to notice that increasing $\alpha$ the maximum swirl velocity moves towards the radial distance of $2.0 \mathrm{~cm}$ which corresponds to the bowl radius. Thus, increasing $\alpha$ is equivalent to increase the swirl ratio in the bowl region. This statement is confirmed by the emissions trends of figure 6 . The NO levels increase monotonically with the swirl profile parameter up to $10 \%$. If $\alpha$ is increased from 0 to 3.11 , soot decreases $(10 \%)$, while an additional increasing to 3.83 lead to higher soot values This result can be explained with the interaction of the fuel sprays generated by the higher swirl velocity in the bowl.

\section{Effect of constants used in spray and combustion models}

\section{Breakup model $\left(\mathrm{B}_{1}\right)$}

The breakup time proportionality constant $\mathrm{B}_{1}$ is assumed to be related to initial disturbance levels originating within the injector nozzle, which are not specified in the linear stability theory. According to Reitz, in the absence of a detailed understanding of the effect of nozzle flows on spray breakup, the breakup time model constant must be determined empirically for each investigated injector nozzle.

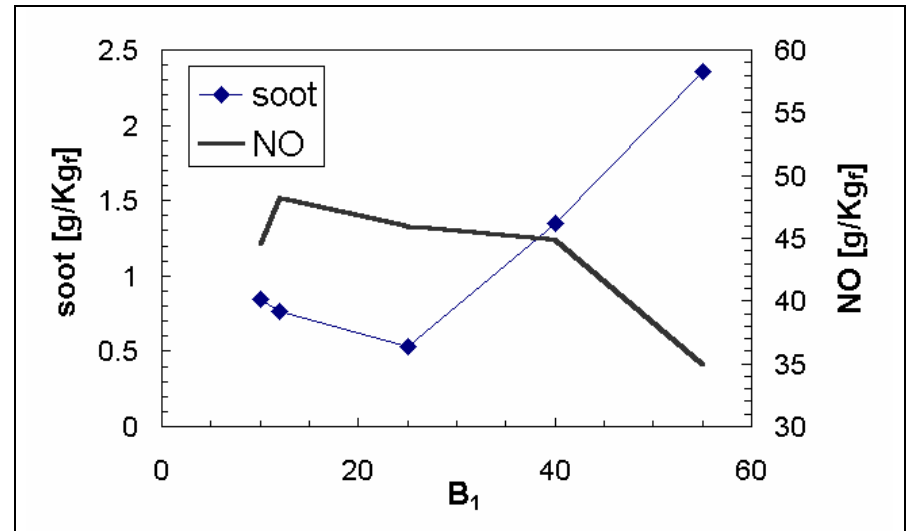

Figure 7 - Emission levels versus breakup characteristic time constant.

The breakup length scale $\mathrm{B}_{1}$ determines the time necessary to perform breakup. Therefore, a lower value of $B_{1}$ results in smaller droplets which can more easily vaporize and burn during the premixed combustion phase. As a consequence of this, the NO decreases ( $30 \%)$ and soot becomes 3 times as high as the baseline case when the constant $B_{1}$ is increases from 25 to 55 . On the contrary, for values of $\mathrm{B}_{1}$ from 10 to 25 the NO weakly increase and soot diminishes (50\%). The emissions trend versus $\mathrm{B}_{1}$ are shown in figure 7 .

This result can be explained with the competition between a faster vaporization and a reduced tip penetration in the case of small sized sprays. Smaller droplets are more sensitive to aerodynamic forces which reduce spray penetration and increase the fuel concentration in the inner region of the combustion chamber. At the same crank angle and with the same injection velocity, the droplets of a low penetration spray are concentrated in a smaller volume, which decreases towards the spray axis due to the reentrant bowl shape. Although small droplets produce more vaporized fuel, the air fuel mixing is limited to the air contained in the bowl volume and the soot emissions increase.

\section{Combustion model $\left(\mathrm{A}, \mathrm{C}_{2}\right)$}

The constant A (eq. 26) is usually varied according to engine grid resolution. In particular, for each engine grid, A is changed in order to match a baseline experimental pressure trace and is successively kept constant as the operating conditions are changed [18]. 


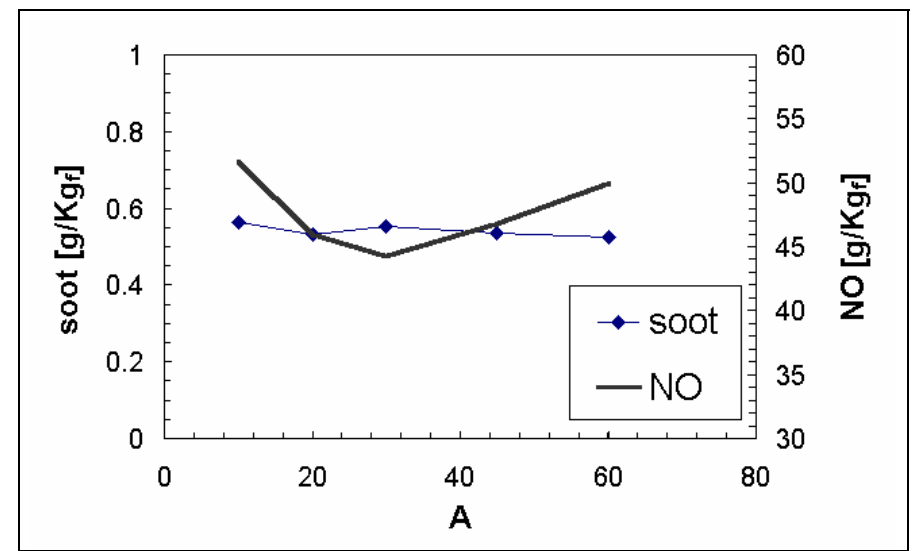

Figure 8 - Emission levels versus laminar characteristic time constant

Numerical simulations performed with A ranging from 10 to 60 show that the pressure peak and the ignition delay are almost constant for the analyzed operating condition, while the pressure rate of changing during the premixed combustion phase increases with A. In fact, the laminar characteristic time, which is related to A, directly affects the initial phase of combustion. By increasing $\mathrm{A}$, the heat released during premixed combustion phase increases and the formation of soot is delayed by the higher oxidation rate.

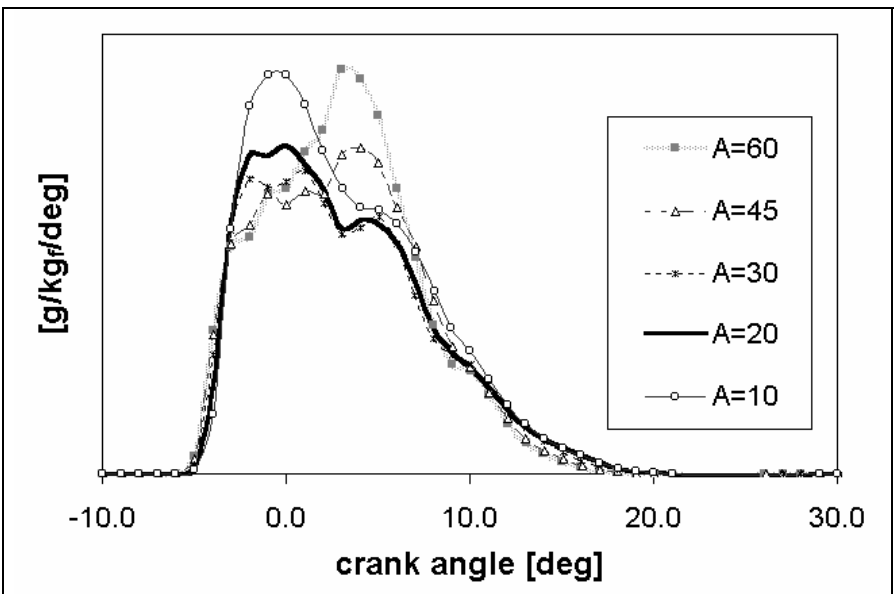

Figure 9 - NO rate of change versus crank angle for different values of $A$.

Results in figure 8 show that the increasing of the laminar time scale doesn't result in a monotonic variation of soot (up to 5\%) and NO (up to $16 \%$ ). This can be explained by recalling that NO production and soot oxidation are governed by both local temperature and oxygen concentration. As the laminar chemistry is enhanced, the faster premixed combustion produces an increasing of local temperature and a decreasing of the local oxygen available for $\mathrm{NO}$ formation and soot oxidation.
The effect of lack of oxygen is showed in figure 9: the higher A, the lowest the initial NO rate of change during the premixed burning phase. However, if the temperature is kept sufficiently high and oxygen is provided by mixing with fresh air, there is a second peak in the NO rate of change during the mixing controlled combustion phase. The magnitude of this peak is proportional to the value of A.

The competition of these mechanisms result in level of NO which decrease by $16 \%$ for A increasing from 10 to 30 and increases by $12 \%$ for higher values of $\mathrm{A}$.

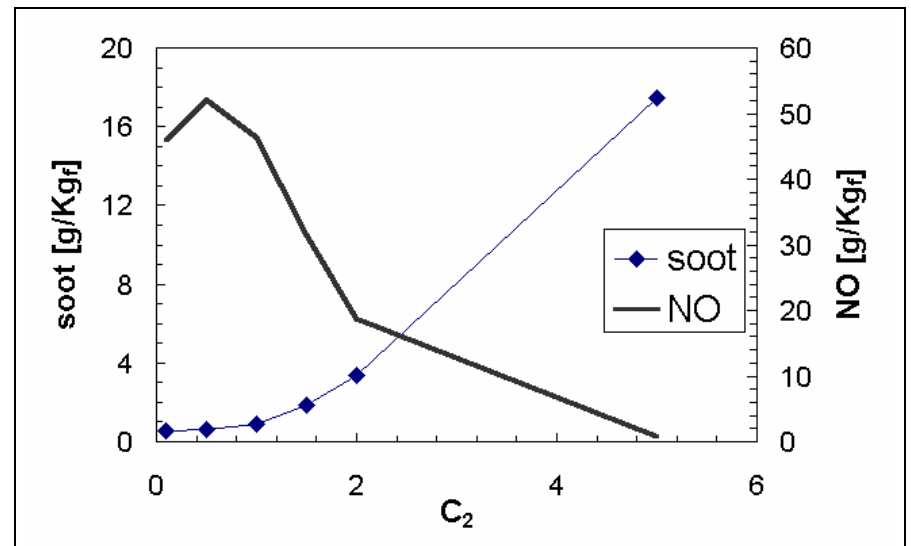

Figure 10 - Emission levels versus turbulent characteristic time constant

The constant $\mathrm{C}_{2}$, which is directly linked to the turbulent characteristic time, eq. (27), has a very strong influence on both pressure traces and emissions levels. For $\mathrm{C}_{2}$ ranging from 0.5 to 3.0 the pressure peak diminishes by $15 \%$, the NO decreases up to $100 \%$ and soot becomes 30 times as high as the baseline case. Pressure traces and emission trend vs. $\mathrm{C}_{2}$ are shown in figure 10. The inversion in the pressure peaks and NO trend for $\mathrm{C}_{2}$ ranging from 0.1 to 0.5 is due to the blow-by process. In fact, when the combustion delay is reduced, the increasing of pressure before the top dead center produce an enhanced flow of mixture through the crevice volumes which decreases the pressure peaks and consequently the maximum temperature reached in the combustion chamber.

\section{SUMMARY AND CONCLUSIONS}

In the present investigation a modified version of the Kiva $3 \mathrm{~V}$ code has been used to test the effect of several input constants, including the both numerical and physical parameters, on the predicted emission levels. Numerical parameters include variables related to breakup, turbulence, and combustion models that are adjusted according to grid resolution, engine and injection system geometry and operating conditions. In particular the effect of laminar and turbulent time scales, characteristic breakup length and time scales, initial turbulence kinetic energy density and initial swirl velocity profile on engine emissions was analyzed. The investigated physical 
parameters were initial swirl ratio, air water content and Schmidt number for mass diffusion.

This study was carried out for a common-rail direct injection small bore diesel engine for which experimental data was available. The simulations were performed starting from a baseline set of these parameters and changing one parameter at a time.

Numerical results showed that some input quantities (Rs, $\mathrm{K}_{0}$, A, HUMIDITY, RSC) give roughly the same pressure trace but modify the predicted emissions levels. Others influence both the average cylinder pressure and the $\mathrm{NO}_{\mathrm{x}}$ and/or soot levels.

Thus, the choice of these parameters for each investigated case should be guided by the following suggestions. On the one hand, accurate numerical data should be used to describe the injector system and engine specifications. On the other hand, complete 3D simulations which include the intake port geometry and moving valves should be performed in order to set up the correct initial conditions of spray and combustion event in the engine.

\section{ACKNOWLEDGMENTS}

The financial support to this research was provided by the Italian Ministry for University and Scientific and Technological Research (MURST).

\section{REFERENCES}

1. Rutland, C.J., Ayoub, N. , Han, Z., Hampson, G., Kong, S.-C., Mather, D., Musculus, M., Patterson, M., Ricart, L., Stephenson, P. , Reitz, R.D. , 1995, "Progress towards Diesel Combustion Modeling", SAE Paper 952429;

2. Rutland, C.J., Eckhause, J., Hampson, G., Hessel, R., Kong, S., Patterson, R., Pierpont, D., Sweetland, P., Tow, T., Reitz, R.D. , 1994 , “ Toward Predictive Modeling of Diesel Engine Intake Flow, Combustion and Emissions”, SAE Paper 941897;

3. Zhang, D., Frankel, S.H., 1998, "A Numerical Study of Natural Gas Combustion in a Lean Burn Engine", Fuel, vol. 77 No 12, pp. 1339-1347;

4. Ogawa, H., Matsui, Y., Kimura, S., Kawashima, J., 1996, "Three-dimensional Computation of the Effects of the Swirl Ratio in Direct-Injection Diesel Engines on $\mathrm{NO}_{\mathrm{x}}$ and Soot Emissions", SAE paper 961125,;

5. Kondoh, Hara, M., Sesumi, K. , 1990, "Study of Some Correction Factors for Application to Stationary Diesel Engine $\mathrm{NO}_{\mathrm{x}}$ data", Proc. of ISME-KOBE '90, Vol. 1, Paper No. C-1-4, pp. 25-32;

6. Ishida, M., Chen, Z. , 1994, "An Analysis of the Added Water Effect on NO Formation in D.I. Diesel Engines", SAE Paper 941691;

7. Yi, J., Yang, J., Anderson, R.W., 1999, "A Study on Turbulent Schmidt Number Dependency on Grid Size in
Numerical Simulations", Paper No 99-ICE-233, Vol. 33-2, 1999 Fall Technical Conference ASME;

8. Amsden, P. J. O'Rourke, T. D. Butler, 1989, KIVA II - A Computer Program for Chemically Reactive Flows with Sprays, Los Alamos National Labs, LA - 11560 MS;

9. Han, Z., Reitz, R. D. , 1995, "Turbulence Modeling of Internal Combustion Engines Using RNG-k- $\varepsilon$ Models", Combustion Science Technology, vol. 106, pp. 207;

10. Wahiduzzaman, S., Ferguson, C. R. , 1986, "Convective Heat Transfer From a Decaying Swirling Flow within a Cylinder", $8^{\text {th }}$ International heat transfer conference, Paper \#86-IHTC-253;

11. Dukowicz, J. K, 1980, “A Particle-Fluid Numerical Model for Liquid Sprays", Journal of Computational Physics, 35, pp. 229-253;

12. Reitz, R. D., Bracco, F. V. , 1982, "Mechanism of Atomization of a Liquid Jet", Phis. Fluid, Vol. 25, No. 10 ;

13. Su, T. F., Patterson, M.A., Reitz, R.D., Farrel P.V., 1996, "Experimental and Numerical Studies of High Pressure Multiple Injection Sprays", SAE Paper 960861;

14. Beale, J. C., Reitz, R.D., 1999, “ Modeling Spray Atomization with the Kelvin-Helmoltz/Rayleigh Taylor Hybrid Model", Atomization and sprays, Vol. 9, pp 623650 ;

15. Senecal, P.K., 1997, "Exploring Alternatives to Conventional DI Diesel Combustion Systems Using Computational Fluid Dynamics", Master Thesis, University of Wisconsin;

16. Halstead, M., Kirsh, L., Quinn, C., 1977, "The Autoignition of Hydrocarbon Fuels at High Temperature and Pressure - Fitting of a Mathematical Model", Combustion Flame, Vol. 30, ps. 45-60;

17. Abraham, J., Bracco, F. V., Reitz, R. D., 1985 "Comparison of Computed and Measured Premixed Charge Engine Combustion”, Combustion Flame, Vol. 60, pp. 309322.

18. Kong, S.C., Han, Z., Reitz, R.D., 1995 “The Development and Application of a Diesel Ignition and Combustion Model for Multidimensional Engine Simulation", SAE paper 950278 ;

19. Hiroyasu, H., Nishida, K., "Simplified Three Dimensional Modeling of Mixture Formation and Combustion in a D.I. Diesel Engine", SAE Paper 890269;

20. Nagle, J., Strickland-Constable, R. F. , 1962, “Oxidation of Carbon between 1000-2000 ${ }^{\circ} \mathrm{C}$ ", Procedure of the Fifth Carbon Conference, Vol. 1, Pergammon Press;

21. Stephenson, P.W., Claybaker, P.J., Rutland, C.J., 1996, "Modeling the Effects of Intake Generated Turbulence and Resolved Flow Structures on Combustion in DI Diesel Engines", SAE paper 960634; 
22. Uludogan, A., Foster, D.E., Reitz, R.D. , 1996, "Modeling the Effect of Engine Speed on the Combustion Process and Emissions in a DI Diesel Engine", SAE paper 962056. 